\title{
Metrics and versification in poetry and song: the 14th Nordic conference on metrics, 13-15 September, 2018, Stockholm, Sweden
}

\section{Sissel Furuseth*}

For more than thirty years, the Nordic Society for Metrical Studies (NORDMETRIK) has arranged conferences across Sweden, Finland, Norway, Denmark, and Iceland, at fourteen different venues so far. The last installment of the NORDMETRIK conference series - Metrics and versification in poetry and song - was co-organized by Stockholm University and the Swedish Academy with Professor Tomas Riad as the prime mover. For three days in mid-September, seventy scholars from five continents, from a wide range of disciplines, gathered in Stockholm to elucidate the complexities of metrics and versification.

The Call for Papers took as its starting point that "metrics and versification constitute a natural meeting point for several disciplines including linguistics, literary studies, musicology, cognitive poetics, philology, linguistic anthropology, folklore, aesthetics, and more". As the conference unfolded it confirmed the premise of the Call. Metrics is certainly a field of study shared by scholars with quite diverse affiliations. Obviously, such an interdisciplinary meeting point also bears some evidence of being an epistemic battlefield, but in the very battle we also find the true value of interdisciplinary gatherings: scientific notions that stand testing from peers outside one's own field of expertise are more solid and reliable than notions never questioned from outsiders.

It is not an easy task, however, to organize a conference with such diverse approaches as were the case in Stockholm, but Metrics and versification in poetry and song was sensibly focused on the language/music interface. In the paper sessions the problem of text-setting, i. e. the alignment of text to music, was addressed by a number of excellent researchers, such as Kristin Hanson (Händel), Rosalía Rodríguez-Vázquez (Galician folk songs), Teresa Proto and Farida van Eer (Dutch rap), Jacqueline Pattison Ekgren (Norwegian stev), Heini Arjava (Finnish songs), Timothée Premat (medieval French song poetry), and

\footnotetext{
* Author's address: Sissel Furuseth, Niels Henrik Abels vei 36, Henrik Wergelands hus, 0313 Oslo, Norway. E-mail: sissel.furuseth@iln.uio.no.
} 
David Paterson (rewriting Japanese lyrics in English), illustrating how a field of research can be diversified and concentrated at the same time.

We have seen it before: music connects people. Researchers from musicology, ethnography and folklore (such as Linda Barwick, Mahesh Radhakrishnan, EevaLiisa Bastman and Kati Kallio, and Frog) seem to take on the role as mediators between more disparate positions such as quantitative metrics on the one hand and cognitive poetics on the other. This is probably due to the power of the empirical events which are in the focus of attention in research where the examples almost speak for themselves, whereas metrical studies at a more abstract level tend to create epistemic conflicts, between generativists and cognitivists, for instance, or between diachronic and synchronic oriented researchers.

The keynote lectures pinpointed the central coordinates within the field of metrical studies, even though the most marked differences between quantitative and qualitative approaches became visible in the paper sessions. The first lecture, given by Sissel Furuseth, Professor of Nordic Literature at the University of Oslo, showed how the music of the Norwegian composer Edvard Grieg is embedded in a single poem written by the Swedish Nobel Prize winner Tomas Tranströmer ("En konstnär i norr"), and was thus an example of how critical interpretations of single texts still play a crucial role for literary scholars standing in the hermeneutical tradition.

In the second plenary session, Francois Dell and Romain Benini from CNRS Paris and Université Paris-Sorbonne, respectively, explained the relationship between grammatical structure and metrical structure in the alexandrine couplets of Jean Racine. Reporting on two components of concordance, cohesion and congruence, they showed that the grammatical constituents that play a central role in concordance are those of prosodic structure, although reference to syntactic structure cannot be completely avoided. Thus, the Dell and Benini lecture contributed to a major topic in metrical studies today, namely the interest in the interplay of prosody and syntax.

Myfany Turpin from the Sydney Conservatorium of Music delivered the third plenary lecture in which she applied linguistic theory, speech act theory and anthropological perspectives addressing the question "Why should interpretive difficulty be a feature in poetry and song?", that is, in central Australian Aboriginal song. Generous with examples from field work studies she made the lecture a magical journey, letting the audience experience the multi-functional character of indigenous song and their place specific performances.

Whereas the three first plenary lectures were held at the Stockholm University Campus in Frescati, the Saturday keynote was located in the distinguished hall of the Swedish Academy in Old Town Stockholm. Patrik Bye, Associate Professor of English Language and Linguistics at the Nord University 
in Bodø (Norway), presented an intriguing argument on the relation between meter, end-stopping and enjambment based on a big corpus of more than 100 English poems, over 4000 verse lines, written between year 1500 and 2000. His main conclusion was that tetrameter lines have weaker boundaries than trimester lines and permit greater variation. With reference to Jakobson and Kiparsky, Bye built his argument basically on prosodic factors, while the question how print culture has influenced on enjambment was not in the focus of attention.

Most of the papers were thematically and methodically grouped around the four plenary talks, some of them focusing on single literary works (from a wide specter of languages), some of them more linguistically oriented with claims on general application, some of them analyzing actual performances of song, and some of them doing statistical analyses of big corpora. However, while none of the plenary lectures spoke up for radical forms of machine reading, some of the papers were more ambitious in that respect. Igor Pilshchikov and Vera Polilova from the Lomonosov Moscow State University presented a new online information system on comparative poetics as a tool for studying the history of Russian and European verse. One of the most important functional capabilities of this digital system is full-text lexical search and specialized attribute search focused on the prosodic (metrical) features of the poetic text. The database is still under construction, but even at this stage it looks very promising with regard to future metrical research across languages. Undoubtedly, the growth of digital humanities has been a blessing for metrical studies the last couple of decades, giving impetus to a new interest in typology as well.

When NORDMETRIK arranged its first conference in Gothenburg, Sweden, September 1987, all in all 27 scholars gathered under the heading Metrik idag (Metrics Today). Twenty of the participants back in 1987 (nearly 75\%) lived and worked in Sweden, three in Finland, two in Norway, one came from Denmark, and one from Iceland. All the papers were presented in the variety of Scandinavian languages and dialects represented at the conference, except from the Icelandic contribution (Kristjan Arnason from Reykjavik was allowed to present his research English). Now, three decades later, the situation is markedly changed. In 2018, it goes without saying that the conference language of NORDMETRIK is English. At the $14^{\text {th }}$ Nordic conference on metrics in Stockholm nearly seventy scholars participated, but only four of the papers were presented by Swedes. We had the pleasure to listen to researchers from Australia, Russia, Colombia, Estonia, the Czech Republic, France, Spain, Germany, USA, the Netherlands, Portugal, and Japan. The Nordic Society for Metrical Studies is certainly interwoven with a continuously expanding international network of scholars. This expansion is highly appreciated. 